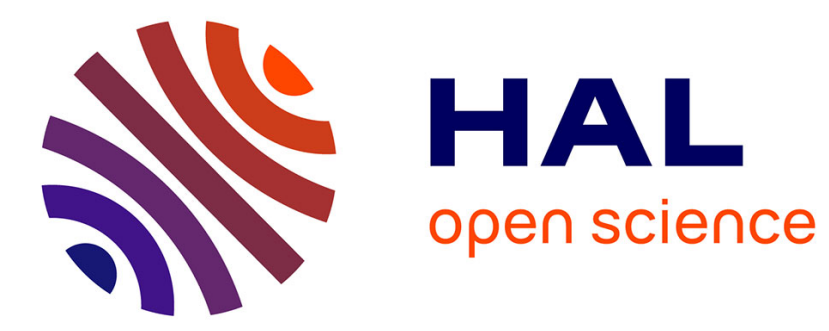

\title{
How to Lead to Sustainable and Successful IT Project Management? Propose 5Ps Guideline
}

\author{
Hamed Taherdoost, Abolfazl Keshavarzsaleh
}

\section{To cite this version:}

Hamed Taherdoost, Abolfazl Keshavarzsaleh. How to Lead to Sustainable and Successful IT Project Management? Propose 5Ps Guideline. International Journal of Advanced Computer Science and Information Technology (IJACSIT), 2015, 4, pp.2296 - 1739. hal-02546794

\section{HAL Id: hal-02546794 \\ https://hal.science/hal-02546794}

Submitted on 23 Apr 2020

HAL is a multi-disciplinary open access archive for the deposit and dissemination of scientific research documents, whether they are published or not. The documents may come from teaching and research institutions in France or abroad, or from public or private research centers.
L'archive ouverte pluridisciplinaire $\mathbf{H A L}$, est destinée au dépôt et à la diffusion de documents scientifiques de niveau recherche, publiés ou non, émanant des établissements d'enseignement et de recherche français ou étrangers, des laboratoires publics ou privés. 
International Journal of Advanced Computer Science and Information Technology (IJACSIT)

Vol. 4, No. 1, 2015, Page: 14-37, ISSN: 2296-1739

(c) Helvetic Editions LTD, Switzerland

www.elvedit.com

\section{How to Lead to Sustainable and Successful IT Project Management? Propose 5Ps Guideline}

\section{Authors}

Hamed Taherdoost

Advanced Informatics School, Universiti Teknologi Malaysia

Research \& Development Department, Ahoora Ltd (Management

Consultation Group)

Abolfazl Keshavarzsaleh

Faculty of Business and Law, International University of Malaya-Wales hamed.taherdoost@gmail.com Kuala Lumpur, Malaysia

abolfazl.keshavarz.saleh@gmail.com Kuala Lumpur, Malaysia

\section{Abstract}

Projects failure may negatively affect the whole implementing enterprise and there is empirical evidence that failure is a persistent trauma within project-oriented organizations. However, it is necessary to know why majority of IT projects fail and what the perceived success/failure factors are and to what extent the risk management concept is of central importance in every IT projects. This study aims to put spotlight on the importance of IT projects success/failure factors and IT project risk factors comprehensively according to literature review. Accordingly, it is proposed 5Ps (Presiding, People, Pragmatic, Process, and Performance) as preventative and proactive measures that IT project managers may consider in order to gain sustainable IT project management development processes. This research indicates how 5Ps consideration will lead to sustainable and successful IT project management.

\section{Key Words}

IT Project Management, Success/Failure Factors, Risk Mitigation, Sustainable Project, Successful Project

\section{INTRODUCTION}

It seems to certain that failure is an inherent part of every type of projects, especially in project-centered organizations (Lindahl and Rehn, 2007). Moreover, IT projects are not exception because of their complexity and volatility as to be expected by planners and project managers. As 
it is statistically indicated, the abandoned or total failure projects are around 20-30 percent and around 30-60 percent of projects fail because of lack of cost and time advantage over competitors or other common problems (Standish, 2013). On the other hand, optimistically only 29 percent of projects are succeed reportedly (Taylor, 2000).

Additionally, as recent study illustrated that failures appear to be more significant in public sphere are roughly 84 percent and consequently, occur in a costly manner (Royal Academy of Engineering and British Computer Society, 2004). Accordingly, association of salaried medical specialists in 2003 is revealed that across both public and private sectors, around \$ US 150 billion is wasted per annum on IS failures in the United States and \$US140 billion in the European Union. Alarmingly, IT managers worst fears were realized when the rate of software project failure rates remain increasingly high despite soaring investment in information technology in the context of organizations significantly (Hong and Kim 2002; Baccarini, Salm et al. 2004; Bannerman 2008; El Emam and Koru 2008; Altuwaijri and Khorsheed 2011).

In conformity with, the CHAOS Manifesto 2013 (Standish 2013) only 39 percent of software projects were successful, in terms of what it set out to do as an objectives such as on-time and onbudget accomplishment, with all perceived functions and features. On the other side, another 43 percent of projects were challenged, completed and operational but without keeping within a budget, estimated time and without fulfilling reliable deliverables than originally specified. Finally, the remaining 18 percent of software projects have failed before completion and never used.

Overwhelming majority of researches is specified that only 10 percent were successful, 52 percent were challenged and 38 percent have failed in mega soft ware projects. Furthermore, this indicates that software projects failure may negatively affect the whole implementing enterprise (Hong and Kim 2002; Lavbič, Vasilecas et al. 2010; Bernroider, Wong et al. 2014).

As it is discerned nowadays in project-oriented glob, majority of organizations are sentenced to do projects profitably. But the fact of the matter is that organizations should more concentrate in fulfilling projects successfully. It has been published a comprehensive review on project success which is deeply emphasized on the project success and project management success (J udgdev and Muller 2005; Ika 2009). Therefore, Munns and Bjeirmi (1996) defined project management as "the process of controlling the achievement of the project objectives by applying a collection of tools and techniques". Highly regarded influential factors that cause failure of the projects are identified by many researchers such as an inadequate basis for the project, the wrong person as project manager, talks inadequately defined, lack of technical project management, lack of commitment to the project (Munns and Bjeirmi 1996) time, cost, and customer satisfaction (Thomas and Fernandéz 2008) and also specifically the management model (Haughey 2010). Moreover, there is a wide range of literatures on information technology project failures comprising both theory and case study that is pinpointed as technical, managerial, planning, resourcing, and environmental factors (Heeks 1999). Unquestionably, software projects are made 
manifest in its complex projects as high risk activities due to the rapid pace of revolutionary technological and the organizational changes, that may impose (Cule, Schmidt et al. 2000; Hong and Kim 2002; Aloini, Dulmin et al. 2007; Kwahk and Kim 2007; Bannerman 2008; Altuwaijri and Khorsheed 2011; Li, M.-H. et al. 2011).

As success/failure factors are tied with project success/failure, therefore, the importance of risk management toward success of the projects is undeniable. As a result, the importance of risk management have been highlighted by (Baccarini, Salm et al. 2004; Tiwana and Keil 2004; Wallace L, Keil M et al. 2004). Notably, considerable researches have been conducted in case of risk factors which classified in both frameworks and checklists (Bannerman 2008) as well as stepwise tasks, also known as process models, are widespread in theory and practice (Aloini, Dulmin et al. 2007; Bannerman 2008).

As Rockhart and Crescenzi (1984) has pointed out, critical success factor approach is crucial in managing any projects and later on redefined by (Bullen and Rockhart 1981; Rockhart and Crescenzi 1984) for the purpose of measuring and identifying organization's performance. Recently, critical success factor method has also been considered in software development projects. Literally, Bullen and Rockhart (1981) defined critical success factors as the guarantee for competitive performance considering for the individual, department, or organization for the purpose of flourishing business and achieving manager's goal and consequently, covers managerial techniques (Reel 1999) as well as combination of software engineering and business strategy (Bytheway 1999). On the plus side, Bosghossian (2002) defined development life cycle and estimation and validation to executive management, project management, and resource and strategic-level planning as critical success factors. While there is much published research on IT project management success/failure factors and likewise other spheres, still a disciplined investigation on project success/failure and risk factors has been largely disregarded. By studying all aforementioned matters, we gain comprehensive insight beyond hitherto importance of IT project management success/failure factors. In this writers' opinion, any failure in deducing success/failure factors and managing, importantly mitigating risk factors will lead to not only project failure but also failure in meeting organization's objectives.

The presented study research seeks to put spotlight on the importance of IT projects success/failure factors and IT project risk factors comprehensively according to literature review. Accordingly, it is proposed 5Ps (Presiding, People, Pragmatic, Process, and Performance) as preventative and proactive measures that IT project managers may consider in order to gain sustainable IT project management development processes. The finding of this study will attract interest of enthusiasts to have an extensive source of information as organized materials. Therefore, we seek to capture reader's attention in reflecting upon how 5Ps consideration will lead to sustainable and successful IT project management. The last but not least, the results are pertinent to IT project managers, information system practitioners, and researchers in the field of management information system for the purpose of meeting what they set out to do optimistically and confidently. 


\section{THEORETICAL BACKGROUND}

Project management and its success are totally related together, but not in direct way (Munns \& Bjeirmi, 1996). In regard with the importance of critical success factors, critical success factors are the fundamental of project success and will never guarantee the success solely and consequently focus upon providing high performance in both current operation activities and future success (Andrew C Boynton and Zumd 1984). Hence, the project can either be successful even when managed badly or can fail even though it was managed in a well manner.

Unquestionably, project management is central to the importance of project success and IT projects also are not exceptional. Project management is defined internationally with consideration of successful fulfillment. Accordingly, IPMA (2006) in the IPMA Competence Baseline (ICB) states a project as "a time and cost constrained operation to realize a set of defined deliverables with consideration of the scope to fulfill the project's objectives, up to quality standards and requirements".

Traditionally, the criteria success factors of projects define as time, budget, and requirements (Bakker et al. 2009). This structure, though criticized, is routinely used to determine the success factors in almost all projects considering project plan and its values as well as project delivery and actual values with consideration of project execution and success/failure factors as core spheres.

As long as the importance of success or failure factors are made manifest within the competitive and complex IT project managements concept, preventing software project failure became the main objective of software process improvement as it aims at lowering the costs of development work, shortening the time to market, and improving product quality (Burr and Owen, 1996). Therefore, it seems certain that providing crucial outline for IT project managers or information system experts such as project control considering the important factors differ across projects, the approach fails to account for the dynamic of social, organizational and political life that surround any information system projects will lead to success optimistically.

Generally speaking, success research cited in the literature is mostly accordance with case studies or meta-data analysis such as Specifically, Highsmith (2002) reports from direct experience with agile implementations, while Schatz and Abdelshafi (2005) provide results from the primavera case study, and Karlstrom and Runeson (2005) give insight from the Star-Gate case study. Moreover, other researchers (Boehm and Turner 2003; Augustine, Payne et al. 2005; Ceschi, Sillitti et al. 2005) are concentrated in comparative flavor between traditional and agile methods. Success without consideration of probable risks is not achievable, therefore, risk management is perceived as an inherent part of all projects, specifically complex IT projects. Reportedly, it seems certain that software projects are fraught with risks, with many risks common to nearly all projects and is defined, (Schmidt et al. 2001).

Central to importance of information technology as a source of competitive advantage 
regionally and globally is the question of why IT projects failure rates are still pioneer? And how IT project managers can tackle this problem? Furthermore, IT becomes a core competency in all business spheres and organizational spending on IT applications is increasingly soaring and consequently become a dominant part of the capital budget in a wide range of organizations.

According to verified literatures so far, we clustered the overwhelming majority factors in IT project success as 5Ps; Presiding, People, Pragmatic, Process, and Performance in Figure 1. Therefore, most of the characteristics are routinely found in litterateurs in an unordered manner, in this respect the 5Ps corroborate and organize finding from previous success/failure factors. Notably, the characteristics that this study has found to be most influential in IT project management practicing toward sustainable IT management development processes significantly.

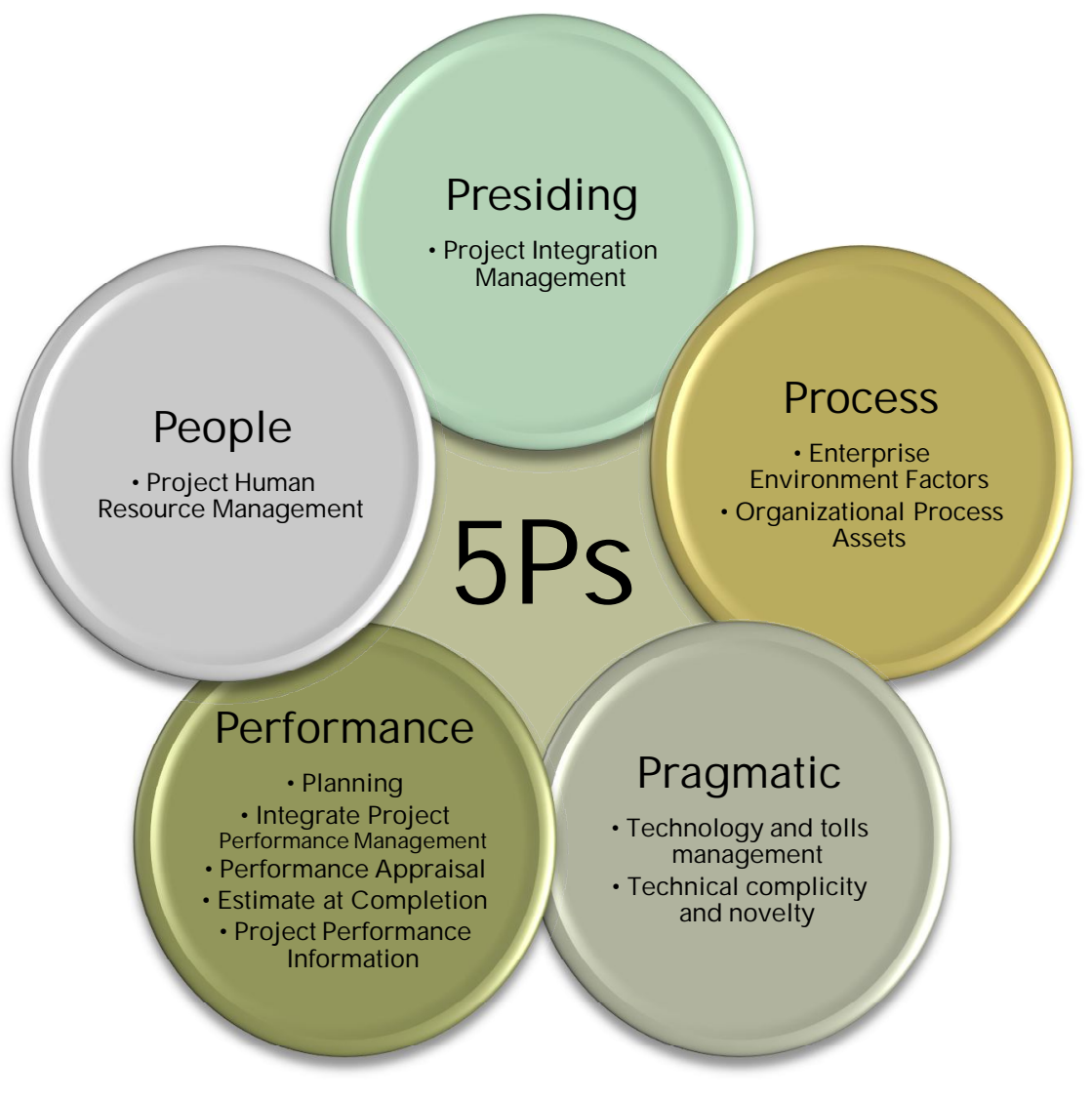

FIGURE I: IT PROJ ECT SUCCESS 5PS

According to the professional body of knowledge (PMBOK) the increasingly perception of project management indicates that the the application of appropriate knowledge, skills, tools and techniques can have substantial impact on project success (PMBOK, 2008). Additionally, the PMBOK guideline identifies that subset of the project management body that is generally considered as good practice. To illustrate "generally recognized' stands for the knowledge and practice described are applicable to most projects most of the time and consequently there is widespread consensus about their value and usefulness. On the other side, "good practice" means 
there is general agreement that the correct application of these skills, tools, and techniques can enhance the chances of success comprehensively (PMI, 2004).

There is empirical evidence that IT spheres have been attracted many researchers interests. In spite of the problem with providing commonly accepted definition of project failures, there is little doubt that failed projects are considered as they do not deliver anything, deliver a product later than expected, or deliver a product that is not useful at all for client that finally lead to not only indirect waste of project resources likely to be substantial, but also the indirect waste such as lost business opportunities (J ørgensen, 2014).

It seems to certain that product success and project success are backbone of every success. Hence, Atkinson (1999) and DeLone and McLean (2003) are stated that project success and project management are interrelated encompasses time, cost and functionality objectives and product success is associated with outcomes of the final product or software, measured by system, information quality, user satisfaction and finally net benefits.

From managerial perspectives, success intervals include short-term, medium-term, long-term and very long term. Shenhar and Levy (1997) recognized the success factors dimensions in terms of aforementioned intervals according to timeframe of expected results:

- A short term goal of project efficiency considering traditional factors such as meeting cost, time, and goals

- A medium term goal is central importance to customer success considering, meeting technical specifications, functional performance, solving customer's problem that initiated the project right through to matching intangible and tangible (Nogeste 2006)outcomes.

- A long term goal of business success interpreted as commercial success and obtaining increased market share that consequently lead to confidence, satisfaction and also influence.

- $\square$ A very long term goal of preparing for the future considering, updating and upgrading in terms of developing new tools, techniques, products, and markets etc.

Unquestionably, the importance of taking proactive, preventative measures as well as analyzing the cause of failure is outweigh why the failure occur (Rooney and Vanden Heuvel 2004). Moreover, failure is an inherent part of any undertaking that involves creating a new service or product is fraught with peril, particularly in complex IT projects in which they regularly fail. Reportedly, over 50,000 IT projects between 1992 to 2004, only 29 percent could be classified as successes (J ohnson, 2006). Accordingly, most of the project failure classified as failure to meet the approved schedule, achieve cost objectives, and provide the expected project scope. Additionally, Lyytinen and Hirschheim (1987) categorized failure factors comprehensively as; correspondence failure where the system could not meet what set out to do in terms of objectives and specifications, process failure when the system is not capable of developing 
within allocated budget or schedule, interaction failure comprising user attitude, satisfaction, and implementation of out-performance and unnecessary task, and expectation failure whereas system does not meet stakeholder requirements, expectations, or values.

According to literature review, majority of researchers conducted research about failure/success factors such as Reel (1999) that identified failure factors even before a design or a line of code is written. Additionally, the problems, mistakes, and misunderstandings in agile processes from a macro point of view is studied by Cohn and Ford (2003) as well as in micro point of view is verified by Larman (2004). Furthermore, management challenges in implementing agile projects are of central importance in people, process, and technology dimensions of migrating to agile projects (Nerur, Mahapatra et al. 2005). Therefore, the 5Ps concept introduced as complimentary framework for sustainable success development in volatile projects especially, IT projects.

\section{A. Presiding}

On the eve of the twenty first century, management is perceived as the key to a successful project, therefore, it is absolutely necessary to evaluate following managerial perception; behavior and technical skills, potential for leadership, personal strengths and weaknesses and experience, factors because they strengthen the chance of better management performance (Haughey, 2010). According to presiding concept in project management project manager is of the essence in all aspects of project management. Moreover, IPMA (2006) indicates that the project manager "is not responsible for achieving the business benefits of the project, which accrue to and are largely realized by the organization once the project is delivered". Therefore, the projects characteristics and organizations policy are considered as crucial indicators as well as the majority of real projects are of a completely different character and organizations rarely run only one project at the time (Gustavsson and Zika-Victorsson, 2008).

Ultimately, success factors that not only implemented by national but also multinational organizations are verified as adequacy of company-wide education, maturity of an organization's processes, portfolio and programme management practices, a suite of projects, a program and portfolio metrics and an effective means of "learning from experience" on projects (Cooke-Davies 2002).

In accordance with the importance of presiding perception in various types of projects, corporate culture and organizational change are undeniably important (Mwaura et al. 1998). In addition, J ung et al. (2008) identified elements that make up the culture and asserted that culture can have a significant effect on multinational companies when a new management practice is implemented in a particular location. Regarding the importance of presidency, leadership is manifesting its self within the organization considering leaders' behavior, attitude and aptitude and how people react to considerable changes such as innovation (Fishman and Kavanaugh, 1989). Therefore, culture is identified as one of the areas wherein the main reasons for failure in projects is to be found, but there are those who discourage the relationship of the cultural dimension with success and failure in projects (Muriithi and Crawford, 2003). To sum up, a relationship is perceived between culture, manager and his management as well as the 
factors that lead to failure or success needs to take into consideration significantly. Also, success of projects in different organizational conditions is verified by Hyväri (2006) in a relevant cross industry study.

Effective and efficient project management and administration is important in presiding concept. Therefore, Crawford (2000) restructured managerial frame work as the role of top management support in project mission, communication and trouble shooting, project scheduling/planning.

Additionally, on the other hand, Cooke-Davies (2001) identified main factors of front- end planning and project definition work; dear mission and vision including unanimous goals, agreed success criteria and clear understanding of desired and expected values, project plan and programme/method including provision of adequate reserves and contingencies, resource planning/identification, project competencies and project management skills, external influences with regard to adequate and agreed organization structure, portfolio and programme management considering corporate strategy and business objectives, lesson learned perception through combination of explicit knowledge with tacit knowledge in a way that encourages people to learn and to embed that learning into continuous improvement of project management processes and practices, and last but not least integrity, effective communication, commitment, support, team approach, mentoring, and learning.

In another research by Tsun Chow and Cao (2008), success factors from organizational, managerial views are illustrated as rigorous executive support, committed sponsor or manager, cooperative organizational culture such as oral culture in terms of valuable, face-to face communication, agile-based methodology organizations, team building and collocating, integrated infrastructure and agile-style work environment, and reward system appropriate for agile. They indicated that in order to have successful projects these factors should be considered frequently. As long as success and failure are the same side of the coin, lots of researches have been conducted about failure factors as well. Furthermore, Tsun Chow and Cao (2008) asserted that apart from success factors, the failure factors might be considered in volatile projects and consequently classified them as lack of executive sponsorship and management commitment, conventional and political-based organizational culture, over-sized organization, and finally lack of agile logistical arrangement.

Also other researchers put spotlight on that the failure factors are central importance in various projects (Murray 2000; Meredith, S.J . Mantel et al. 2002) as unrealistic project scope given the available resources, improper management of scope creep, the organization's issues are not understood., custom work is needed for the organization's business activities. Ultimately, DeLone and McLean, (2003) provided the summary of the common causes of software project failures into four holistic categories; top management, policies, business domain and lately, organizational structures. 
We considered presiding as the first $\mathrm{P}$ in 5Ps concept for the purpose of superior management in all types of projects either complex or volatile that will lead to sustainable management.

\section{B. People}

Major concern of project management and project success consist of how success is judged (success criteria), and the factors that contribute to the success of projects (success factors) (Crawford 2000) as well as study of success criteria, an exploratory re-examination by Lim and Mohamed (1999) conducted through looking at projects where some stakeholders perceive success and others do not on the same project reveals the importance of people concept in almost all projects. Accordingly, there are many issues are associated with project failure identified as poor communication among stakeholders, managers and the project team causes a project serious problem since the team comprises various professionals who interact for the benefit of all. Moreover, the role of people and communication simultaneously shows that a failure at any point in the process causes a dysfunction which interrupts the way that the message is completed. Chiavenato (2005) said that "communication is the process of transmitting information from one person to another person interactively.

Therefore, many researches indicated the importance of people such as personnel, client acceptance, and dient consultation (Crawford 2000), Cooke-Davies "investigated the factors of project success, success in project management and factors for continual success of project realization, citing the omission of the human factor as the only possible omission in their research and (Cooke-Davies, 2001) key stakeholder/key resource, and project management capacity identification emphasizing experience and staff/senior manager's support including project governance, dispute resolution procedures to engender trust behaviors. Therefore, the human factor is considered in an implied manner and is omitted as a determinant of the extent of project success (Cooke-Davies, 2002).

Central to the importance of human as an key indicator in every projects, Tsun Chow and Cao (2008) asserted that competent team members, great motivation, managers know-how in agile process, managers with light-touch and adaptive style, and superior customer relationship are influential in success.

On the other side, Tsun Chow and Cao (2008) claimed that underestimation of failure factors might lead to failure; therefore, they classified failure factors as lack of technical know-how, lack of competent project management, lack of team work, groups or individuals resistance and ultimately wrong and bad customer relationship.

Nothing helps an individual more than to be given responsibility and to know they are competent in the project concepts. Kerzner (2009) acknowledged the fact that human dynamics play an important role in project management failure, citing poor motivation, productivity, and human relations; lack of employee and functional commitment and unresolved policy and stakeholder issues. Therefore, DeLone and McLean (2003) illustrated the common cause of software project failures as social interaction, skills, motivation, customers, external agents, 
users, project team and corporation.

People as vibrant element of each project is discussed as second $\mathrm{P}$ in $5 \mathrm{ps}$ concept considering feeling part a successful project team is part of the engagement process in order to achieve a sustainable project development in projects, especially IT project management.

\section{Process}

For all but the smallest projects, experienced project managers utilize well-established and tailored project management methodologies considering zero defect processes. The traditional view of how the success of a project is measured uses three criteria: time, budget and requirements (Bakker, Boonstra et al. 2009). Hence, the significant number of researchers highlighted the failure factors in terms of process such as Tsun Chow and Cao (2008) with consideration of project scope, project requirements, lack of agile progress tracking mechanism, lack of customer presence and customer role as well as project development experie (Murray 2000). Additionally, Tsun Chow and Cao (2008) categorized success factors in terms of process as Agile-oriented requirement management process, Agile-oriented project management process, Agile-oriented configuration management process, Communicative and daily face-to-face meetings, Honoring regular working schedule, not overtime, Strong customer commitment and presence and Customer with full authority.

Having a plan with a sufficient level of details while consisting the particular flexibility is central to process concept as third P in 5Ps concept which is clarified by (PMBOK, 2008) as enterprise environment factors (EEF) encompasses internal factors (organizational culture, organizational structure, internal political conditions, available resources) and external factors (government regulation, market condition, infrastructure, external political conditions), plus this organizational process assets (OPA) comprising primary (politics, procedure, standard template, and general guideline) and secondary (risk register, lesson learned, stakeholder register, past project files, and historical.

\section{Pragmatic}

Software development and It technology, much like manufacturing are drastically altering. Therefore in order to stay dominant and on top, project managers must be aware of the importance of pragmatic part of each project as well as adapt and accept to change. Regarding the importance of pragmatic perception as fourth P of 5Ps concept, lots of researchers highlighted related success factors such as well-defined coding standards up front, pursuing simple design, rigorous refactoring activities, complete documentation, regular delivery of software, delivering most important features first, proper integration testing and appropriate technical training to team (Tsun Chow and Cao 2008), technical task (Crawford 2000), project tools (Crawford 2003) and on the other hand, related failure factors as lack of complete set of correct agile practices, in appropriation ot technology and tools (Tsun Chow and Cao, 2008), undeveloped project that could 
not deal with new technology (Murray, 2000) and finaly DeLone and McLean (2003) introduced summary of the common causes of software project failures as Project complexity, Available assets, Technology, Requirements and Contracting.

\section{E. Performance}

It is important to keep the triple pillars of time, budget and more important performance in mind all the times. Performance measurement are specific to each project, therefore, we introduce performance as the last but not least P in 5Ps concept. Accordingly, various historical methods of evaluating success encounter barriers to performance measurement is defined by Ramage and Armstrong (2005) apart from difficulties which arise in ensuring the measurement instruments in terms of guarantee reliability, validity and responsiveness. To assist in the categorization of factors impacting on these aspects, they extend the framework developed by de Lancer J ulnes and Holzer (2001) to produce a more comprehensive categorization of influences. These may closely aligned, fortuitously, with the antecedents to Project Management Best Practice or Success in order to come as a relief to Project Management research world.

In accordance with significance of performance in IT project management, Crawford (2000) identified performance factors lead to project success as monitoring and feedback, Cooke-Davies (2001) highlighted as scope management, maintained performance measurement, an effective benefits delivery and management process and finally Tsun Chow and Cao (2008) as non-life critical project nature, project with various scope considering emergent requirements, projects with dynamic, accelerated schedule, project with manageable team, project with no multiple independent teams, projects with up-front evaluated cost, and projects with up-front analyzed risks.

On the other side of the coin, performance factors which lead to failure in projects are identified by Kerzner (2009) as delayed problem solving and summary of the common causes of software project failures (DeLone WH and ER. 2003) as software testing and quality control.

Finally, we highlight that project management metrics enable project managers to appraising, foreseeing, and ultimately having a sustainable development and success in IT projects through aforementioned key performance indicators.

\section{Risk Man Agement ANd Mitigation}

The benefits of risk management in projects are tremendous. According to project management institute's PMBOK, risk management is one of the ten knowledge spheres in which project manger must be competent (PMBOK 2008). Good project risk management is solely associated with supporting organizational factors, clear roles as well as technical analysis skills such as planning risk management, risk identification, performing quantitative and qualitative risk analysis, planning risk responses and monitoring and controlling risks. Moreover, negative consequences of underestimating risk and its factors is identified by Aubert, et al. (2001) as risks related to the client (as members of the project team, as an organization, as part of management and as users of the completed system), risks related to the vendor (as members of the project 
team and as an organization entrusted to provide a service), risks relating to elements and activities of the outsourced strategic it development project itself, from pre-contract to post contract (Abdullah 2008; Abdullah 2009).

In accordance with the significance of IT projects, Verner and Abdullah (2012) clarified in such complex factors encompasses; complexity, contract, financial, legal, scope and requirements, planning and controlling and execution respectively. Furthermore, identifying and classifying of risk factors are studied in various researches (Boehm and Ross 1989; Barki, Rivard et al. 1993; Ropponen and Lyytinen 2000; Keil, Cule et al. 1998; Tiwana and Keil 2004; Wallace L, Keil M et al. 2004; Kappelman, McKeeman et al. 2006; Tesch, Kloppenborg et al. 2007). However, few studies have paid attention to the risk evaluation processes in IT project management. Accordingly, Keil et al. (2000) introduced a comprehensive framework including the influence of personal, project, informational, and organizational factors. As it is perceived software project are considered as high risk activities because they cannot keep pace with technological changes and organizational changes as well (Aloini, Dulmin et al. 2007; Altuwaijri and Khorsheed 2011);(Bannerman 2008; Cule, Schmidt et al. 2000; Hong and Kim 2002; Kwahk and Kim 2007; $\mathrm{Li}, \mathrm{M}$.-H. et al. 2011). Therefore, the importance of risk and risk management as a crucial project success factor is manifested itself increasingly (Baccarini, Salm et al. 2004; Tiwana and Keil 2004; Wallace L, Keil M et al. 2004) and recently is highlighted frequently in why usually software projects fail (de Bakker, Boonstra et al. 2010) as well as.

Majority of researchers have been identified lack of effective management as one of the main failure factors in software project risk management (Aloini, Dulmin et al. 2007; Bannerman 2008; de Bakker, Boonstra et al. 2010; Geraldi, Kutsch et al. 2011; Kappelman, McKeeman et al. 2006; Kutsch and Hall 2005; Osipova and Eriksson 2013). Therefore, there is a significant need to highlight the particular factors that may influence the risk perception of information technology project managers. Hence, Shapira (1995) discussed the relationship between post decisional control in risky situations and managerial skills. Additionally, Ropponen and Lyytinen (2000) highlighted the related factors to project failure such as controllability of outcomes, and risk perception and software environment. Ultimately, Wallace et al. (2004) have identified six dimensions of project risks: organizational environment risk, user risk, requirements risk, project complexity risk, planning and control risk, and team risk. Managerial control over risk factors is classified by Keil et al. (1998) and Tiwana and Keil (2004) as endogenous and exogenous risk factors comprising project team morale, employee productivity, inadequate training, or inadequate project reviews ( $\mathrm{ani}, 2008)$. Hence, software projects are subjected to organizational risks (Benaroch et al. 2006; Sanderson 2012; Sharma and Gupta 2012) because they are difficult to manage and knowledge of risks alone is not enough to contribute to project success (de Bakker et al. 2010; Thamhain 2013). Central to importance of IT projects risk assessment, the six-item risk perception scale was created by Keil et al. (2000):

- Likelihood that the project will meet the budget goal,

- Likelihood that the project will meet the schedule goal, 
- Estimate of cost overrun, and schedule overrun

- Probability of project success and overall risk

The fact of the matter is that, the first two items tap into the probability of negative outcomes and the next two items tap into the 'magnitude of potential loss or negative outcomes significantly.

It seems certain that in all complex IT projects success and failure are the same side of the coin. This would suggest that it might be necessary to identify and control both success and failure factors and risk factors in order to have successful project. We classified all risk factors both influential and weighty as 5Ps concept which are central to the importance of risk and its control and mitigation in Table 1.

TABLE I: RISK CRITERIA ASSOCIATED WITH 5PS

\begin{tabular}{|l|l|}
\hline \multicolumn{1}{|c|}{ 5Ps } & \multicolumn{1}{c|}{ Risk Criteria } \\
\hline Presiding & Plan Risk Management \\
\hline People & Perform Qualitative Risk Analysis \\
\hline Process & $\begin{array}{l}\text { Plan Risk Reponses } \\
\text { I dentify Risks }\end{array}$ \\
\hline Pragmatic & Perform Quantitative Risk Analysis \\
\hline Performance & Monitor And Control Risks \\
\hline
\end{tabular}

Presiding: Presiding or organizational risk management is risk management at the strategic level. Presiding as core cluster in risk management is not one-size-fits- all solution but it is crucial enough to be considered. Therefore, Verner and Abdullah (2012) highlighted risk factors at strategic and managerial level as changing in organizational management (Benaroch 2002; Wallace et al. 2004) (poor change management, poor project governance, poor project leadership, poor project management, poor project planning, organizational change inadequately addressed, unstable business and organizational environment that affected the project), corporate politics with negative effect, corporate culture not supportive, lack of top executive support, different geographical locations (socio-political instability, trade barriers, uncertainty about the legal environment), organizational restructuring, poor cultural fit between client and vendor, privacy and security intrusion (inadequate protection of intellectual property) and requirements (conflicting requirements, incorrect requirements, inadequate requirements, unclear requirement) (Benaroch 2002; Wallace et al. 2004).

Furthermore, Cooke-Davies (2001) introduced feasibility analysis in terms of resources, contingencies, risk and outcomes, as well as company-wide education on the concept of risk management, and risk taking capabilities considering maturity of an organization's processes for assigning ownership of risks.

Unquestionably, these aforementioned risk factors force critical thinking and shift energy to optimal performance in risky environment of complex projects such as IT projects. The secret of risk management positioning is to establish a presiding structure within the organization that 
enables dissention and cooperation will lead to desired research culture at strategic level.

People: There is empirical evidence that people are not only the significant asset in any types of projects but also the vulnerable assets as well. Moreover, the key to delivering successful projects consistently is people which are introduced as second P of 5Ps concept. Therefore, Verner and Abdullah (2012) highlighted risks related to people as client (in terms of lacks cooperation, lacks trust, lack of ability to gain information), communication problems, conflict between dient $\&$ vendor, divergent working styles, imperfect commitment, lack of experience $\&$ expertise ( in terms of outsourcing, contract management, the project tasks), lack of required skills, loss of key employees, negative attitudes, team composition, vendor's moral hazard and overstated daims , users (Benaroch 2002; Wallace et al. 2004) (in terms of conflict, size, lack of user participation, non-willing users and unrealistic expectations) team risks. In relation to one or many, of the reasons above, considerable focus is upon people and perception. Consequently, people skills have to be adeptly integrated into the sustainable IT project development and the excellence team and expert emergence.

Process: Managing risks on projects is a process indudes risk assessment such as identification risks and evaluation of their impacts on project success and a mitigation strategy for those risks. A more disciplined process involves using checklists of potential risks and evaluating the likelihood of them. Therefore, Verner and Abdullah (2012) highlighted risk indicators as lack of readiness to implement, logistical complications, inadequate disaster recovery operations, incompatible development choices, changing \& creeping objectives/scope/requirements considering unrealistic estimation of schedule \& required resources and noncompliance with specified methodologies and low visibility of project process.

Process concept as an important part of 5Ps concept in risk management can help narrow the focus on a few critical risks that require mitigation. Accordingly, Benaroch (2002) and Wallace et al. (2004) are recognized the influential risk factors in IT investment such as competition risks, and market environment risks. Additionally, Cooke-Davies (2001) identified risk factors as documentation of organizational responsibilities on the project, and rational project stage duration (Keep project or project stage duration) as far below 3 years as possible (1 year is better). Most projects are subject to constant risks of meeting their objectives, therefore, risk register and risk register update are central to importance in any types of IT projects (PMBOK 2008).

Pragmatic: The fact of the matter is that, having a standard way of stating and communicating a risk provides clarity and consistency. Pragmatic concept focuses upon technical perspectives in risk management through recognizing conditions and consequences. Therefore, Verner and Abdullah (2012) clarified risk factors from technical point of view as high level of technical complexity (Benaroch 2002; Wallace et al. 2004), highly complex task, significant integration \& customization required, use of new technology, technological discontinuity, and performance problems. An effective pragmatic risk management will result to project success according to 
technical significance.

Performance: Performance metric is to measure the performance as well as project progress. the Earned Value Management (EVM) concept as defined by PMI standard PMBOK, is the commonly used method (PMBOK 2008). Therefore, related factors which is associated with performance in risk management and mitigation introduced by Verner and Abdullah (2012) as failure to specify appropriate measures and non-performance penalties, nonflexible performance, contract in favor of vendor, currency exchange fluctuations, hidden costs, insufficient funds, poor systems of authority and poor audit, quality assurance $\&$ control and last but not least poor user expectations management.

Additionally, it seems to certain that the performance management in project risk management considers as crucial task, therefore, completion risks (Benaroch 2002; Wallace et al. 2004), making risk register visible (with which a visible risk registers is maintained) and up-to date risk management plan are central to importance in performance management, correspondingly, risk management in projects.

\section{Discussion}

Most of these characteristics are routinely found in overwhelming majority of IT projects. In this respect, the 5Ps corroborate findings from previous failure studies. Notably, the factors that these studies have found to be most influential in the case of either failure or success were all concrete traits of the $5 \mathrm{ps}$ experience; project integration management, planning, integrate project performance management, performance appraisal, estimate at completion, project performance information, enterprise environment factors, organizational process assets; technology and tolls management, technical complicity and novelty and project human resource management are success criteria acting as spring board toward project prosperity. On the hand, plan risk management, perform qualitative risk analysis, monitor and control risks, perform quantitative risk analysis, plan risk responses, identify risks are introduced as risk criteria in order to guarantee success of all aspects of projects.

Some success/failure studies are focused on the various factors that influence project success or failure. However, the focused of this research tends to be on presiding, people, process, pragmatic and finally performance not only from success/failure point of view but also from risk management and its mitigation. Moreover, most of the literatures, by nature, do not pinpoint such influences comprehensively, correspondingly, profoundly. Beyond the literature on software, IS, IT project success/failure, finding suggests that 5Ps can expose productivity. Studies have also highlighted the importance of organizational capacity as a driver of successful projects in terms of success criteria and risk criteria which introduced in this research in order to gain sustainable IT projects.

Despite its limitation, this research has provided some interesting interpretations for practitioners. While the theoretical analysis validates some perceptions, it also provides some surprises. First of all the findings agree with many of principles in project management, 
software, and agile projects (Martin 2003). Therefore, regarding the importance of research on volatile and complex projects, we expect to see future research concentrating on the cause and effect relationships between factors, pre-adoption as well as post adoption analysis, prioritizing of factors in IT , IS, software development projects. Table 2 summarizes the 5Ps concept exhibited several characteristics.

TABLE II: 5PS CONCEPT

\begin{tabular}{l|l|l}
\hline \multicolumn{1}{c|}{ 5ps } & \multicolumn{1}{c}{ Success /F ailure Criteria } & \multicolumn{1}{c}{ Risk Criteria } \\
\hline Presiding & Project Integration Management & Plan Risk Management \\
\hline People & Project Human Resource Management & Perform Qualitative Risk Analysis \\
\hline Process & $\begin{array}{l}\text { Enterprise Environment Factors(EEF) } \\
\text { Organizational Process Assets (OPA); }\end{array}$ & $\begin{array}{l}\text { Plan Risk Reponses } \\
\text { Identify Risks }\end{array}$ \\
\hline Pragmatic & $\begin{array}{l}\text { Technology And Tolls Management } \\
\text { Technical Complicity And Novelty }\end{array}$ & Perform Quantitative Risk Analysis \\
\hline Performance & $\begin{array}{l}\text { Planning } \\
\text { Integrate Project Performance } \\
\text { Management } \\
\text { Performance Appraisal } \\
\text { Estimate At Completion } \\
\text { Project Performance Information }\end{array}$ & Monitor And Control Risks \\
\hline
\end{tabular}

\section{IMPLICATIONS}

The 5Ps concept can offer lessons for project success guarantee, correspondingly, failure avoidance. In particular, the project managers can address some preventative measures toward sustainable IT project development:

1) To make sure that the risks involved in the project are fully considered and understood clearly , as with 5Ps, the introduced risk criteria checklists may be provide proactive as well as risk management and its mitigation in an environment that the decisions should be taken in volatile and complex conditions.

2) To make sure that key people as key players such as project manager who is responsible to lead the project are in the right designations and there is also consistency throughout the projects as well as before or after introducing product.

3) To make sure all success and failure factors are considered properly, in order to ensure that the end-users see the benefit of the product or output via fully performance management, success/failure factor analysis, and risk management and its mitigation continuously. 
4) To make sure that how IT project managers can react properly in both small or mega projects, regardless of size via using 5Ps conceptualized guideline in order to do pilot study as well as feasibility analysis concomitantly.

This article provides lessons for those involved in IS and IT projects, namely that is appears crucial to be aware of the importance of such criteria in volatile projects.

\section{ACKNOWLE DGMENT}

This research has been prepared and supported by Research \& Development Department of Ahoora Ltd (Management Consultation Group).

\section{REFERENCES}

[1] A. Burr and M. O. (Eds.) (1996). Statistical Methods for Software Quality: Using Metrics for Process Improvement, ITP A Division of International Thomson Publishing Inc.

[2] Agarwal, N. and U. Rathod (2006). " Defining 'success' for software projects: an exploratory revelation." Int. J . Proj. Manage 24(4): 358-370.

[3] Al-Ahmad, W., K. Al-Fagih, et al. (2009). "A Taxonomy of an IT Project Failure: Root Causes." International ManagementReview 5(1): 93-105.

[4] Aladwani, A. M. (2000). "IS project characterestics and performance: A Kuwaiti illstration." journal of global information management 8(2): 50-57.

[5] Aloini, D., R. Dulmin, et al. (2007). "Risk management in ERP project introduction: Review of the literature." Information \& Management 44: 547-567.

[6] Aloini, D., R. Dulmin, et al. (2007). " Risk management in ERP project introduction: Review of the literature." information \& Management 44: 574-567.

[7] Aloini, D., R. Dulmin, et al. (2012). "Risk assessment in ERP projects." Information system and management 37: 183-199.

[8] Altuwaijri, M. M. and M. S. Khorsheed (2011). " A project-based model for successful IT innovation diffusion." International J ournal of Project Management 30: 37-47.

[9] Amram, M., N. Kulatilaka, et al. (1999). manageing busines risks by IT investmnet. Boston review. Boston university.

[10] Andrew C Boynton and R. W. Zumd (1984). "an assessment of critical success factor." Sloan management review 25(4): 17.

[11] Atkinson, R. (1999). "Project management: cost, time, and quality, two best guesses and a phenomenon, it's time to accept other criteri." international project management 17(6): 337-342.

[12] Augustine, S., B. Payne, et al. (2005). "Agile project management: steering from the edges." Communications of the ACM 48(12): 85-89.

[13] B.A. Aubert, M. Patry, et al. (2001). IT outsourcing risk management at British Petroleum. Proceedings of the 34th Annual Hawaii International Conference on System Sciences: pp. 1-13. 
[14] Baccarini, D. (1999). "The logical framework method for defining project success." Proj. Manage. J . 30(4): 25-32.

[15] Baccarini, D., G. Salm, et al. (2004). "Management of risks in information technology projects." Industrial Management \& Data Systems 104: 286-295.

[16] Bakker, K., A. Boonstra, et al. (2009). "Does risk management contribute to IT project success? A meta-analysis of empirical evidence?" International J ournal of Project Management 28(5): 493-503

[17] Bannerman, P. L. (2008). "Risk and risk management in software projects: A reassessment." journal of Systems and Software 81: 2118-2133.

[18] Barki, H., S. Rivard, et al. (1993). "Toward an assessment of software development risk." J ournal of Management Information Systems 10(2): 203-25.

[19] Benaroch M, Lichtenstein Y, et al. (2006). "Real Options in IT risk management: an empirical validation of risk-option relationships." MIS Quarterly 30(4): 827-64.

[20] Bernroider, E. W. N., C. W. Y. Wong, et al. (2014). "From dynamic capabilities to ERP enabled business improvements: The mediating effect of the implementation project." international J ournal of Project Management 32: 350-362.

[21] Boehm, B. and R. Turner (2003). "Using risk to balance agile and plan-driven methods." Computer 36(6): 57-66.

[22] Boehm, B. W. (2000). " Project termination doesn't equal project failure." Computer 33(9): 94-96.

[23] Boehm, B. W. and R. Ross (1989). "Theory-W software project management: Principles and examples." IEEE Transactions on Software Engineering 15(7): 902-916.

[24] Bosghossian, Z. J . (2002). An investigation into the critical success factors of software development process, time, and quality. Malibu, California, Pepperdine University. Ph.D.

[25] Bullen, C. V. and J . F. Rockhart (1981). "A primer on critical success factors." Sloan Manage Review.

[26] Bytheway, A. J . (1999). " Successful software projects and how to achieve them." IEEE Software 16(3): 15-17.

[27] Ceschi, M., A. Sillitti, et al. (2005). " Project management in plan-based and agile companies." IEEE Software 22(3): 21-27.

[28] Charette, R. N. (2005). "Why software fails, perceived effect of softwareengineering practices in the Italian industry." J ournal of Systems and Software 83(10): 1907-1916.

[29] Chiavenato, I., Ed. (2005). Géstion del talento humano, Mc Graw Hill.

[30] Cohn, M. and D. Ford (2003). "Introducing an agile process to an organization." Computer 36(6): 7478.

[31] Cooke-Davies, T. (2001). Towards Improved Project Management Practice: Uncovering the Evidence for Effective Practices Through Empirical Research. PhD. Leeds, Leeds M etropolitan University. 
[32] Cooke-Davies, T. (2002). "The real success factors on projects." International J ournal of Project Management 20(3): 185-190.

[33] Crawford, L. (2000). Profiling the Competent Project Manager. Project Management Research at the Turn of the Millenium. Project Management Institute Sylva, NC. Paris, France: 3-15.

[34] Cule, P., R. Schmidt, et al. (2000). "Strategies for Heading Off is Project Failure. ." information system and management 17: 61-69.

[35] de Bakker, K., A. Boonstra, et al. (2010). "Does risk management contribute to IT project success? A meta-analysis of empirical evidence." Int. J . Proj. Manage 28(5): 493-503.

[36] de Lancer J ulnes, P. and M. Holzer (2001). "'Promoting the Utilization of Performance Measures in Public Organizations: An Empirical Study of Factors Affecting Adoption and Implementation." Public Administration Review 61(6): 693-708.

[37] DeLone WH and M. ER. (2003). "The DeLone and McLean model of information systems success: a ten-year update." J ournal of Management Information Systems 19(4): 9-30.

[38] E.K. Clemons (1991). "Evaluation of strategic investments in information technology." Communications of the ACM 34: 22-36.

[39] El Emam, K. and A. G. Koru (2008). "A replicated survey of IT software project failure." IEEESoftware 25(5): 84-90.

[40] European, C. (2001). "building an innovative economy in Europe." a review of 12 studies of inovation policy and practice in today's Europe 5(11).

[41] Ewausi-Mensah, K. (1997). "critical issues in abandon information syastem development." Communication of ACM 40(9): 74-80.

[42] Fabriek, M., Brand, M.v.d., Brinkkemper, S., Harmsen, F., Helms, R., (2008). Reasonsfor success and failure in offshore software development projects. EuropeanConference on Information Systems: pp. 446-457.

[43] Fishman, N. and L. Kavanaugh (1989). "Searching for your missing quality link." J ournal for Quality and Participation 12: 28-32.

[44] Geraldi, J. G., E. Kutsch, et al. (2011). "Towards a conceptualisation of quality in information technology projects." international J ournal of Project Management 29: 557-576.

[45] Gustavsson, T. K. and A. Zika-Victorsson (2008). "Multi-project settings - too many balls in the air and some on the floor." International journal of project management research( Issue 3).

[46] Haughey, D. (2010). "How to recruit an IT project manager." Project Smart: 1-4.

[47] Heeks, R. (1999). Reinventing government in the information age. London7 Routledge.

[48] Highsmith, J. (2002). Agile Software Development Ecosystems. Addison-Wesley. Boston, Massachusetts.

[49] Hong, K.-K. and Y.-G. Kim (2002). "The critical success factors for ERP implementation: an organizational fit perspective." Information \& Management 40: 25-40. 
[50] Hyväri, I. (2006). "SUCCESS OF PROJ ECTS IN DIFFERENT ORGANIZATIONAL CONDITIONS."." Project Management J ournal 37(4): 31-41.

[51] I ka, L. A. (2009). "Project success as a topic in project management journals." Proj. Manage. J . 40(4): 6-19.

[52] IPMA (2006). IPMA Competence Baseline (ICB). The Netherlands. 3.0.

[53] J .J . Rooney and L.N. Vanden Heuvel (2004). "Root cause analysis for beginners, Qual." Information and Software Technology 37(7): 45-53.

[54] J ani, A. (2008). "An experimental investigation of factors influencing perceived control over a failing project." International J ournal of Project Management 26: 726-732.

[55] J ørgensen, M. (2014). "F ailure factors of small software projects at a gl obal outsourcingmarketplace." The J ournal of Systems and Software 92: 157-169.

[56] J udgdev, K. and R. muller (2005). "a retrospective look at our evolving understanding of project sucess." project Management journal 36: 19-31.

[57] Kappelman, L. A., R. McKeeman, et al. (2006). "Early warning signs of IT project failure: the dominant dozen." Inf. Syst. Manage 23(4): 31-36.

[58] Karlstrom, D. and P. Runeson (2005). "Combining agile methods with Star -Gate project management." IEEE Software 22(3): 43-49.

[59] Keil, M., P. E. Cule, et al. (1998). "A framework for identifying software project risks." Communications of the ACM 41(11): 76-83.

[60] Keil, M., B. C. Y. Tan, et al. (2000). " A cross cultural study on escalation of commitment behavior in software projects." MIS Quarterly 24(2): 299-325.

[61] Keil, M., L. Wallace, et al. (2000). " An investigation of risk perception and risk propensity on the decision to continue a software development projec." The J ournal of Systems and Software Process improvement, CCIS,Springer, Berlin / Heidel berg 53(2): 145-157.

[62] Kerzner, H. (2009). Project management : a systems approach to planning, scheduling and controlling. Wiley \& Sons. Hoboken, New J ersey:.

[63] Kutsch, E. and M. Hall (2005). "Intervening conditions on the management of project risk: Dealing with uncertainty in information technology projects." international J ournal of Project Management 23: 591-599.

[64] Kwahk, K.-Y. and H.-W. Kim (2007). "anaging readiness in enterprise systemsdriven organizational change." management behavioure and information technology 27: 79-87.

[65] L.Kumar, R. (2002). "managing risks in IT projects: an options perspective." Information \& Management: 63-74.

[66] L.M. Abdullah, J . M. V. (2008). Risk framework for outsourced strategic IT system development from the client perspective. Software Metrics European Forum. Milan, I taly: pp.1-12,9-788870-909999. 
[67] L.M. Abdullah, J. M. V. (2009). Outsourced strategic IT systems development risk. IEEE Research Challenges in Information Systems. Fes, Morocco: pp. 309-320.

[68] Larman, C. (2004). Agile \& I terative Development. Addison-Wesley,. Boston, Massachusetts.

[69] Lavbič, D., O. Vasilecas, et al. (2010). "Ontology-based multi-agent system to support business users and management." technology ,economic, development 16: 327-347.

[70] Li, Y., Yang, , K. M.-H., et al. (2011). "The role of team problem solving competency in information system devel opment projects." international J ournal of Project Management 29: 911-922.

[71] Lim, C. S. and M. Z. Mohamed (1999). "Criteria of project success: an exploratory reexamination."." International J ournal of Project Management 17(4): 243-248.

[72] Linberg, K. R. (1999). " Software developer perceptions about software project failure:a case study." J ournal of Systems and Software 42(2): 177-192.

[73] Lindahl, M. and A. Rehn (2007). "Towards a theory of project failure." international journal of management concept philosphy 2(3): 246-254.

[74] Lyytinen, K. and R. Hirschheim, P. r. (1987). Information failures - a survey and classification of the empirical literature., in Oxford Surveys in Information Technology. Oxford U niversity Press, Inc 257309.

[75] M.Benaroch (2002). "Managing information technology investment risk: a real options perspective." J Manage Inform Syst 19(2): 43-84.

[76] M.Benaroch (2002). "Managing information technology investment risk: a real options perspective." J OURNAL OF INFORMATION SYSTEM 19(2): 43-84.

[77] M.Benaroch (2002). " Managing information technology investment risk: a real options perspective." J ournal of Management Information Systems 19(2): 43-84.

[78] Meredith, J . R., S.J . Mantel, et al. (2002). "Project management : a managerial approach."

[79] Munns, A. K. and B. F. Bjeirmi (1996). "The role of project management in achieving project success." T Int. J . Proj. Manage. 14(2): 81-87.

[80] Munns, A. K. and B. F. Bjeirmi (1996). " The role of the Project Management in achieving project success." International J ournal of Project Management,Scotland, UK 14(2): 81-87.

[81] Muriithi, N. and L. Crawford (2003). "Approaches to project management in Africa: implications for international development projects." nternational J ournal of Project Management. 121(3): 309-319.

[82] Murray, J. P. (2000). "Reducing IT project complexity. Information Strategy." The Executive's J ournal 16(3): 30.

[83] Mwaura, G., J . Sutton, et al. (1998). "Corporate and national culture - an irreconcilable dilemma for the hospitality manager?" I nternational J ournal of Contemporary Hospitality Management 10(6): 212-220.

[84] Nahod, M. M., M. Vukomanovic, et al. (2013). "The impact of ICB 3.0 competences on project management success original 
[85] research article." Procedia - Social and Behavioral Sciences(74): 105-115.

[86] Nerur, S., R. K. Mahapatra, et al. (2005). "Challenges of migrating to agile methodologies." Communications of the ACM 48(5): 72-78.

[87] Nogeste, K. (2006). Development of a Method to Improve the Definition and Alignment of Intangible Project Outcomes with Tangible Project Outputs. Graduate School of Business. Melbourne, Melbourne.

[88] Osipova, E. and P. E. Eriksson (2013). "Balancing control and flexibility in joint risk management: Lessons learned from two construction projects." international J ournal of Project Management 31: 391-399.

[89] Pinto, J. K. and D. P. Slevin (1987). " Critical factors in successful project implementation." IEEE Trans. Eng. Manage. EM 34(1): 22-27.

[90] Pinto, J . K. and D. P. Slevin (1988). "Project success: definitions and measurement techniques." Proj. Manage. J. 19(1): 67-72.

[91] PMBOK (2008). "A Guide to the Project Management Body of Knowledge, 4th ed. ." Project Management Institute.

[92] PMI (2004). "A Guide to the Project Management Body of Knowledge.3rd Edition." Sylva, NC, USA Project Management Institute.

[93] Ramage, P. and A. Armstrong (2005). "Measuring success - Factors impacting on the implementation and use of performance measurement within Victoria's human services agencies." Evaluation J ournal of Australisia 5(2): 5-17.

[94] Reel, J. S. (1999). "Critical success factors in software projects." IEEE Software Process Improvement, CCIS,Springer, Berlin / Heidel berg 16(3): 18-23.

[95] Repiso, L. R., R. Setchi, et al. (2007). "Modelling IT projects success: Emerging methodologies reviewed." Technovation 27(10): 582-594.

[96] Rockhart, J . F. and A. D. Crescenzi (1984). "Engaging top management in information technology." Sloan Management Review 25(4): 3-16.

[97] Ropponen, J . and K. Lyytinen (2000). "Components of Software Development Risk: How to address them? A project manager survey." IEEE Transactions on Software Engineering 26(2): 98-12.

[98] Sanderson, J . (2012). "Risk, uncertainty and governance in megaprojects: A critical discussion of alternative explanations." international J ournal of Project Management 30: 432-43.

[99] Schatz, B. and I. Abdelshafi (2005). "Primavera gets agile: A successful transition to agile development." IEEE Software 22(3): 36-42.

[100] Schmidt, R., K. Lyytinen, et al. (2001). "I dentifying software project risks:an international delphi study." J ournal of Management Information Systems 17(4): 5-36.

[101] Shapira, Z. (1995). Risk taking: A managerial perspective. New York., Russell Sage Foundation, . 
[102] Sharma, A. and A. Gupta (2012). "Impact of organisational climate and demographics on project specific risks in context to Indian software industry." international J ournal of Project Management 30: 176-187.

[103] Shenhar, A. J. and O. Levy (1997). "'Mapping the dimensions of project success." Project Management J ournal 28(2): 5-14.

[104] Standish, G. (2013). chaos manifest. , The Standish Group International, Inc.

[105] Taylor, A. (2000). IT projects: Sink or swim. The Computer Bulletin: 24-26.

[106] Tesch, D., T. J. Kloppenborg, et al. (2007). " IT project risk factors: The project management professional 's perspective."J ournal of Computer Information Systems journal 47(4): 61-69.

[107] Thamhain, H. (2013). "Managing risks in complex projects." project Management 44: 20-35.

[108] Thomas, G. and W. Fernandéz (2008). "Sucess in IT Projects: A matter of definition?" International J ournal of Project Management 26(7): 733- 742.

[109] Tiwana, A. and M. Keil (2004). "The one-minute risk assessment tool." Communications of the ACM 47: 73-77.

[110] Tsun Chow and D.-B. Cao (2008). "A survey study of critical success factors in agile software projects." The J ournal of Systems and Software 81: 961-971.

[111] Verner, J ., Sampson, J ., Cerpa, N., (2008). "What factors lead to software project failure?Research Challenges in Information Science." IEEE Computers: 71-80.

[112] Verner, J. M. and L. M. Abdullah (2012). "Exploratory case study research: Outsourced project failure." 54: 866-886.

[113] Wallace L, Keil M, et al. (2004). "Understanding software project risk: a cluster analysis." Inform Manage 42(1): 115-25.

[114] Williams, J . J . and A. Ramaprasad (1996). "A taxonomy of critical success factors." European J ournal of Information Systems 54(4): 250-260.

[115] Cooke-Davies, T. (2001). Towards Improved Project Management Practice: Uncovering the Evidence for Effective Practices Through Empirical Research. PhD. Leeds, Leeds M etropolitan University.

[116] Crawford, L. (2000). Profiling the Competent Project Manager. Project Management Research at the Turn of the Millenium. Project Management Institute Sylva, NC. Paris, France: 3-15.

[117] Crawford, P. a. B., P. (2003). "'"Project monitoring and evaluation: a method for enhancing the efficiency and effectiveness of aid project implementation." International J ournal of Project Management 21(5): 363-373.

[118] J ohnson, J . (2006). "My Life Is Failure: 100 Things You Should Know to Be a Better Project Leader." Standish Group International: 166.

[119] Keil, M., P. E. Cule, et al. (1998). "A framework for identifying software project risks." Communications of the ACM 41(11): 76-83. 
[120] Martin, R. (2003). Agile Software Development: Principles, Patterns, and Practices. Prentice Hall, Upper Saddle River, New J ersey.

[121] Meredith, J . R., S.J . Mantel, et al. (2002). "Project management : a managerial approach."

[122] Murray, J. P. (2000). "Reducing IT project complexity. Information Strategy." The Executive's J ournal 16(3): 30.

[123] PMBOK (2008). "A Guide to the Project Management Body of Knowledge, 4th ed. ." Project Management Institute.

[124] Tiwana, A. and M. Keil (2004). "The one-minute risk assessment tool." Communications of the ACM 47: 73-77. 